\title{
Abnormal dark adaptation kinetics in autosomal dominant sector retinitis pigmentosa due to rod opsin
} mutation

\author{
Anthony T Moore, Fred W Fitzke, Colin M Kemp, Geoffrey B Arden, T Jeffrey Keen, \\ Christopher F Inglehearn, Shomi S Bhattacharya, Alan C Bird
}

\begin{abstract}
The time course of dark adaptation was measured in 10 subjects from three families with autosomal dominant sector retinitis pigmentosa (RP) due to mutations in the first exon of the rod opsin gene. In each subject cone adaptation and the early part of the recovery of rod sensitivity followed the normal time course, but the later phase of rod adaptation was markedly prolonged. The recovery of rod sensitivity is much slower than that reported in any other outer retinal dystrophy. Using a model based upon primate data of rod outer segment length and turnover, we have calculated that the delayed phase of the recovery of rod sensitivity in the $R P$ patients tested following strong light adaptation could be due in part to formation of new disc membrane with its normal concentration of rhodopsin rather than in situ regeneration of photopigment.
\end{abstract}

(Br F Ophthalmol 1992; 76: 465-469)

Research into disease mechanisms in retinitis pigmentosa (RP) is complicatę by heterogeneity within the disorder. RP may be inherited as an autosomal dominant, autosomal recessive, or Xlinked disorder, and there is good evidence of heterogeneity within genetic subtypes. ${ }^{1-13}$ Further subdivision of autosomal dominant RP (ADRP) has been achieved by analysis of functional deficits. Two broad categories of RP have been identified which are designated as class I or 'diffuse' and class II or 'regional' forms, ${ }^{1-4}$ and the functional characteristics appear to be consistent within families indicating that the functional differences reflect genetic heterogeneity. An additional variant, sector $R P$ is characterised by retinal atrophy seen in only one part of the fundus, usually the lower nasal quadrant, and gross field loss confined to the area of visual field corresponding to the involved retina. The rod and cone electroretinographs show mild reduction in amplitude with normal cone implicit times. ${ }^{s-7}$ This pattern of disease is seen in all affected family members, irrespective of age suggesting that the disease, in contrast to other forms of ADRP, is nonprogressive or progresses very slowly.

Recent genetic studies have provided evidence for further heterogeneity in $\mathrm{AD}$ and $\mathrm{X}$-linked

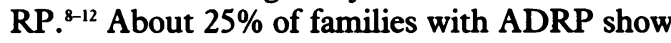
mutations of the rod opsin gene on chromosome $3,{ }^{13} 14$ and among this group of patients different patterns of retinal dysfunction may be seen with different mutations. ${ }^{15-20}$ Recently it has been shown that genes other than that for rod opsin may transmit ADRP. ${ }^{21} 24$

Here we report the clinical, electroretinographic, and psychophysical findings in 10 patients from three families with autosomal dominant sector RP due to mutations in the rod opsin gene. In each of these families there was markedly slowed rod adaptation.

\section{Patients and methods}

Ten affected individuals from three families diagnosed as having sector ADRP were studied (Table 1). Informed consent was obtained after the nature of the procedure had been fully explained. In each patient ophthalmoscopy revealed pigment epithelial atrophy and pigment migration into the lower retina which was most marked in the inferior nasal quadrant. The upper retina had a normal appearance. In each case Goldmann perimetry revealed upper field - loss corresponding to the ophthalmoscopically abnormal retina (Fig 1). Electroretinography was performed in nine subjects in accordance with a standard protocol ${ }^{25}$ (Table 2). Dark adapted perimetry was performed on the right eye of each subject using red (dominant wavelength $660 \mathrm{~nm}$, subtending $0.9^{\circ}$ ) and green (dominant wavelength $530 \mathrm{~nm}$, subtending $0.9^{\circ}$ ) targets. The pupil was dilated with $1 \%$ cyclopentolate and the eye dark adapted for 40 minutes before starting the test. At least 17 points at different retinal locations in both upper and lower fields were tested in each case. The apparatus and method for the dark adapted static perimetry have been described previously. ${ }^{26}$ Dark adaptation curves were obtained from threshold measurements determined using the green $\left(530 \mathrm{~nm}, 0.9^{\circ}\right)$ target of the static perimeter or the Tubinger perimeter (dominant wavelength $500 \mathrm{~nm}$; stimulus size $\left.1 \cdot 7^{\circ}\right)$. We chose to determine the dark adaptation curves at points in the clinically uninvolved retina where the rod threshold elevations were less marked (Table 1). Threshold measurements were made on the right eye. The pupil was dilated, the eye dark adapted for 60 minutes, and a dark adapted threshold was then determined. The area of retina to be tested was then fully light adapted (7.5 log scotopic trolands for 3 seconds) and measurements were continued in the dark for at least 60 minutes (or longer if the patient could tolerate it).

Blood samples were collected from each subject and DNA extracted. Exon sequences were amplified using the polymerase chain reaction (PCR) and screened for mutations using the heteroduplex assay as described pre-

Addenbrookes Hospital,
Cambridge
A T Moore
C M Kemp
Institute of
Ophthalmology, London
F W Fitzke
G B Arden
A C Bird
Department of Human
Genetics, Newcastle'
T J Keen
C F Inglehearn
S S Bhattacharya
Correspondence to:
Mr A M Moore, MA FRCS,
Ophthalmology Department,
Addenbrookes Hospital, Hills
Road, Cambridge, UK.
Accepted for publication
21 February 1992


Table 1 Pre-bleach thresholds and elevation of threshold after 60 minutes of dark adaptation following strong light adaptation. In families 1038 and 1084 the mutation is Gly106Arg, and in 1935 it is Thr58Arg

\begin{tabular}{llllll}
\hline Subject & RP family & Age & Test location & $\begin{array}{l}\text { DA threshold } \\
\text { elevation }\end{array}$ & $\begin{array}{l}\text { Additional threshold } \\
\text { elevation }\end{array}$ \\
\hline 1 & 1038 & 36 & $180 \mathrm{M} 25 \mathrm{E}$ & $0 \cdot 8$ & $1 \cdot 0$ \\
2 & 1038 & 64 & $330 \mathrm{M} 25 \mathrm{E}$ & $1 \cdot 1$ & $1 \cdot 2$ \\
3 & 1038 & 74 & $315 \mathrm{M} 20 \mathrm{E}$ & $1 \cdot 9^{\star}$ & $1 \cdot 1^{\star}$ \\
4 & 1084 & 26 & $180 \mathrm{M} 25 \mathrm{E}$ & $0 \cdot 9$ & $1 \cdot 6$ \\
5 & 1084 & 47 & $345 \mathrm{M} 25 \mathrm{E}$ & $1 \cdot 1$ & $1 \cdot 0$ \\
6 & 1935 & 45 & $315 \mathrm{M} 40 \mathrm{E}$ & $0 \cdot 6^{\star}$ & $0 \cdot 8^{\star}$ \\
7 & 1935 & 18 & $315 \mathrm{M} 50 \mathrm{E}$ & $0 \cdot 5^{\star}$ & $0 \cdot 4^{\star}$ \\
8 & 1935 & $180 \mathrm{M} 25 \mathrm{E}$ & $0 \cdot 1$ & $1 \cdot 9$ \\
9 & 1935 & 21 & $180 \mathrm{M} 40 \mathrm{E}$ & $0 \cdot 0$ & $1 \cdot 4$ \\
10 & 1935 & 50 & $315 \mathrm{M} 30 \mathrm{E}$ & $0 \cdot 1$ & $1 \cdot 6$ \\
& & & $315 \mathrm{M} 40 \mathrm{E}$ & $1 \cdot 5^{\star}$ & $1 \cdot 3$ \\
& & & & $1 \cdot 4^{\star}$ & $2 \cdot 1^{\star}$ \\
\hline
\end{tabular}

-Additional threshold elevation = the elevation over the dark adapted threshold after 60 minutes of adaptation following bleach.

$\mathrm{DA}=$ dark adapted; $M=$ meridian; $\mathrm{E}=$ eccentricity measured in degrees. Thresholds were measured with a LED adaptometer ${ }^{\star}$, or Tubinger perimeter.

\section{Table 2 Amplitudes and implicit times of the electroretinograms}

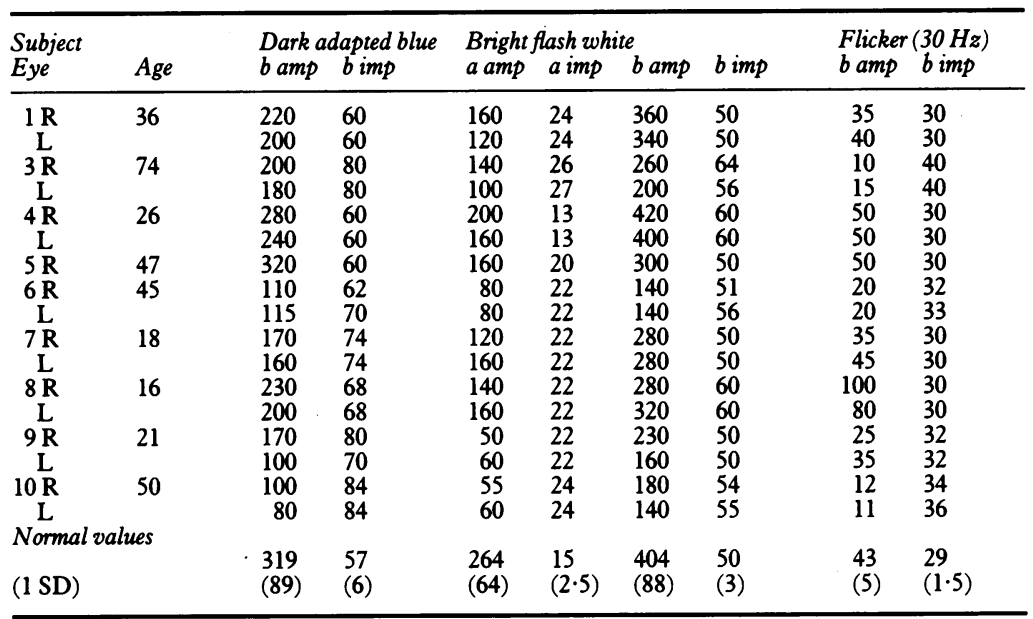

amp=amplitude in $\mu \mathrm{V}$; imp=implicit time in milliseconds; no data are available on subject 2 .

viously. ${ }^{27} 28$ Pairs of oligonucleotide primers were synthesised surrounding rod opsin exons to give PCR products in the range of $200-300 \mathrm{bp}$. The PCR was carried out using a two-stage reaction profile of $94^{\circ} \mathrm{C}$ for 30 seconds and $60^{\circ} \mathrm{C}$ for 3 minutes, repeated 30 times. Aliquots of the PCR reactions mixes were then electrophoresed on D5000 hydrolink gels (AT Biochem, Malvern, PA, USA for around $2000 \mathrm{Vh})$. Mismatches due to the presence of a heterozygous mutation caused shifted mobility in heteroduplexed molecules, which could then be further characterised by sequencing the appropriate PCR product.

\section{Results}

Rod opsin mutations were identified in each family comprising a change of threonine to arginine at codon 58 in RP1935, and glycine to arginine at codon 106 in RP1038 and RP1084. Both mutations can be detected as altered restriction sites in PCR amplified rod opsin exon 1 (Fig 2).

In all subjects Goldmann visual field loss was confined to the upper field, and dark adapted perimetry confirmed that thresholds for both the $530 \mathrm{~nm}$ and $660 \mathrm{~nm}$ targets were markedly elevated throughout that region (Fig 1). In the lower field, which was normal on Goldmann perimetry, dark adapted perimetry was normal in some areas but mildly abnormal in others

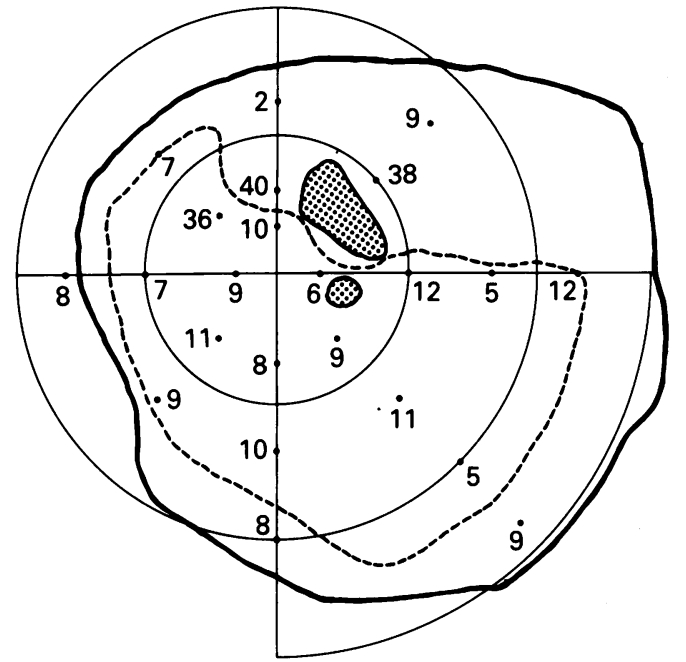

Figure 1 Patient 1: right eye, Goldmann visual fields to IV 4 e (solid line) and IL $4 e$ (broken line) targets. Numerical values indicate dark adapted static perimetry threshold elevation in tenths of a log unit to a green $(530 \mathrm{~nm})$ target).

consistent with the regional pattern of disease. This pattern of threshold elevation was a consistent finding in all 10 subjects.

All subjects had normal or mildly reduced rod and cone b-wave amplitudes of the ERG (Table 2). There was a trend for the amplitudes to become less with age but they did not approach the levels seen in non-sector RP. Rod b-wave implicit times were abnormal in all five members of RP1935 and the oldest member of RP1038. Cone implicit times were normal in at least one member of each family.

Dark adaptation was markedly prolonged in all 10 subjects, and none reached their prebleach threshold by 60 minutes. At this time the threshold elevation relative to the pre-bleach values ranged from $0 \cdot 4$ to $2 \cdot 1 \log$ units (Table 1 ). Inspection of the dark adaptation curves showed that in each case there was a similar pattern of abnormality; cone adaptation was normal, the rod cone break occurred at the normal time, and the early part of the rod adaptation curve followed an apparently normal time course. Subsequently rod adaptation was markedly slowed with a gradual drift down towards the threshold (Figs 3 and 4).

Because of the difficulty with prolonged testing it is not possible to give the exact time for full recovery of rod function. However two subjects agreed to be tested again during the following days. At the end of the initial dark adaptation determinations the subjects returned to normal ambient lighting conditions, and were later retested at the same retinal location at periods ranging from 24 to 120 hours post-bleach. On each occasion the subjects were dark adapted for 1 hour before threshold measurements were taken. Subject 10 showed elevated thresholds of 0.6 and 1.4 logs units above pre-bleach values at two different locations 44 hours after light adaptation, and in subject 7 the threshold was elevated $1.5 \log$ units at 24 hours but had returned to the dark adapted value by 120 hours.

\section{Discussion}

Nyctalopia is a prominent and early symptom in 
Figure 2 (A) Family 1935 pedigree, mounted above a photograph of an ethidium bromide stained gel showing $P C R$ amplified exon 1 from members of the family cut with the enzyme Ddel. PCR primers CATGTTTCTG CTGATCGTGC and ACTCTCCCAGACCCC TCCAT give a 295 bp fragment which is normally uncut with the restriction enzyme Dde 1. However the codon 58 ACG to $A G G$ mutation introduces a Dde 1 site, which gives rise to 254 and 41 bp bands. All affected individuals are heterozygous for the uncut and cut fragments. (B) Family 1038 pedigree, mounted above a gel picture showing PCR amplified exon 1 from family members which has been cut with the restriction enzyme Apal. The same $P C R$ primers were used giving a fragment of $295 \mathrm{bp}$, which is normally cut to 191 and 104 bp

fragments by $A p a$ 1. The codon 106 GGG to $A G G$ mutation destroys this site, so that affected individuals are again heterozygous for digested and undigested product.

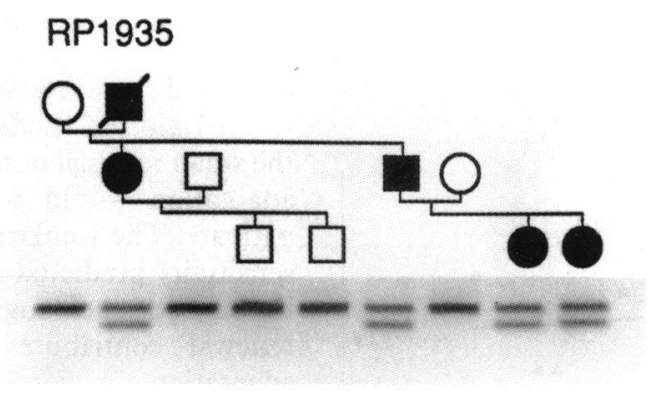

Fig $2 A$

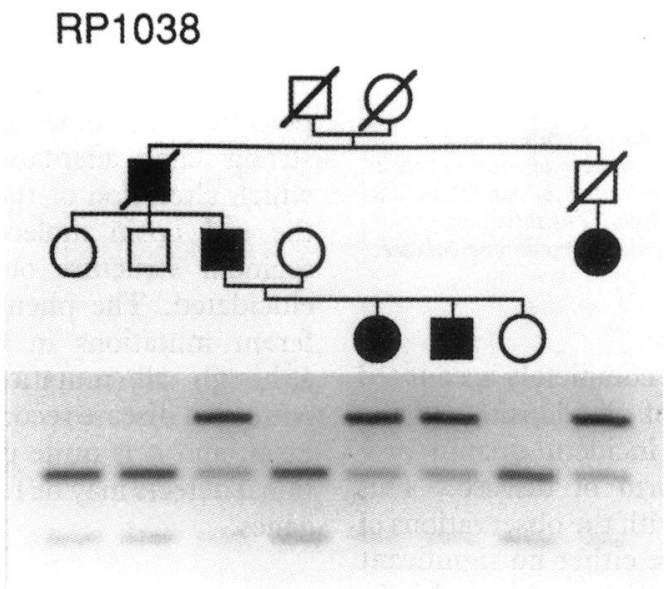

Fig $2 B$

$\mathrm{RP}$, and elevated absolute thresholds are seen in all types of the disease. Where there is extensive loss of rod function, cones may mediate threshold even under scotopic conditions so that the dark adaptation curve is monophasic. In patients with less advanced disease, most studies have identified a biphasic dark adaptation curve with a normal time course but elevated final threshold. ${ }^{29} 30$ However, Alexander and Fishman pointed out that unless a baseline dark adapted threshold is determined before light adaptation it is not possible to be certain that dark adaptation is complete even when thresholds appear to have stabilised. ${ }^{31}$ They identified several patients with different types of RP in whom the final thresholds were elevated and the time course of recovery of

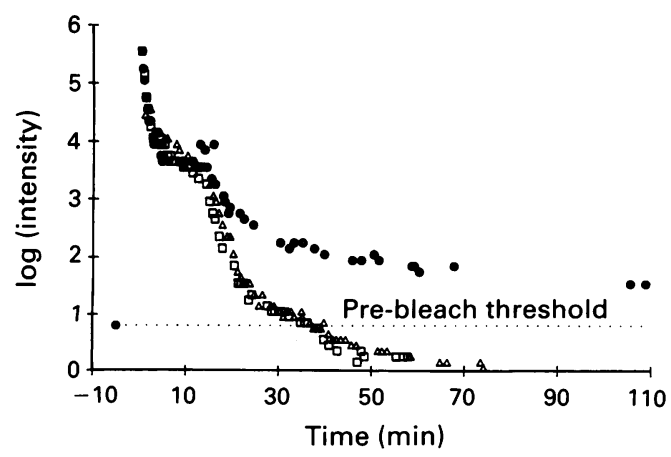

Figure 3 Patient 1: right eye, dark adaptation curve plotted using Tubinger perimeter ( $500 \mathrm{~nm}$ wavelength) at $25 \mathrm{deg}$ eccentricity along the horizontal nasal field meridian. The patient's threshold values (solid circles) and those of two normal observers (open symbols) are plotted relative to normal absolute threshold. The patient's baseline dark adapted threshold is shown as the horizontal line. Adaptation to the $8 \cdot 0$ log scotopic troland seconds light was at time zero.

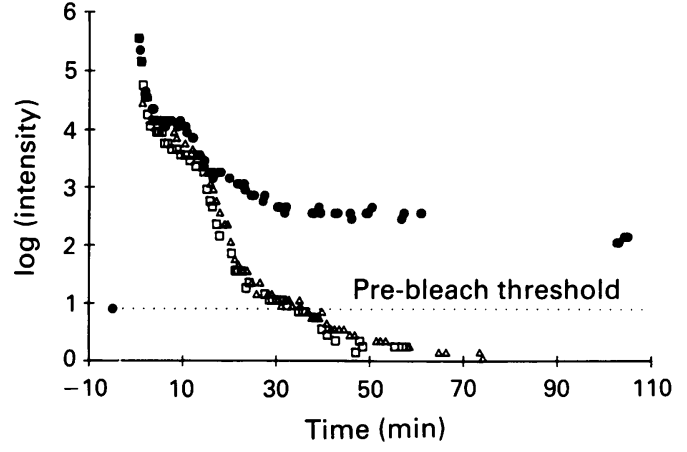

Figure 4 Patient 4: right eye, dark adaptation curve plotted using the Tubinger perimeter (500 $\mathrm{nm}$ wavelength) at 25 degree eccentricity along horizontal nasal field meridian. The patient's threshold values (solid circles) and those of two normal observers (open symbols) are plotted relative to normal absolute threshold. The patient's baseline dark adapted threshold is shown as the horizontal line. Adaptation to the 8.0 log scotopic troland seconds light was at time zero.

rod sensitivity was slow. They did not determine that the abnormality was consistently seen within a family or genetic subtype.

Using a similar approach we have been able to show delayed rod dark adaptation in all 10 subjects from three families with autosomal dominant RP. Our patients resemble those designated as sector $\mathrm{RP}^{\mathrm{s}-7}$ in that altitudinal distribution of disease was found consistently in each family whatever the age of the subject. Although the implicit time of the rod and cone bwaves were not normal in all subjects, normal times were found in at least one member of each family.

The functional abnormality in our patients with a mutation at codon 106 is qualitatively similar to that seen with the mutation at codon 58. Slow rod adaptation has been identified previously in some patients with ADRP, 19203132 including some with altitudinal distribution of disease and known mutations of the rod opsin gene namely: threonine-17-methionine ${ }^{19}$; proline-23-histidine, ${ }^{20}$ and threonine58 -arginine. ${ }^{19}$ Our results are similar to those previously reported although the slow phase of recovery of rod sensitivity was longer in our patients than in each of the other genotypes. There is no clear explanation for this disparity although the light adaptation protocols were different in that we used more light $(8.0 \mathrm{log}$ scotopic troland seconds as opposed to $7 \cdot 5$ ), and it was delivered in a shorter time ( 3 seconds as opposed to 60).

There are several possible mechanisms by which abnormality of the rod opsin molecule could result in slowed adaptation. There may be slowed regeneration of rhodopsin as seen in fundus albipunctatus ${ }^{33}{ }^{3+}$ or delayed removal of abnormal bleach photoproducts which may interfere with rhodopsin formation or desensitise the rod photoreceptors. ${ }^{31}$

Alternatively, it is possible that abnormal rod opsin could interfere with normal disc assembly, structure, or stability. The prolongation of the recovery of rod sensitivity to a period of several days led us to consider whether or not outer segment renewal may contribute to the later phase of dark adaptation in our patients. In our model we have assumed the dark adapted rod 


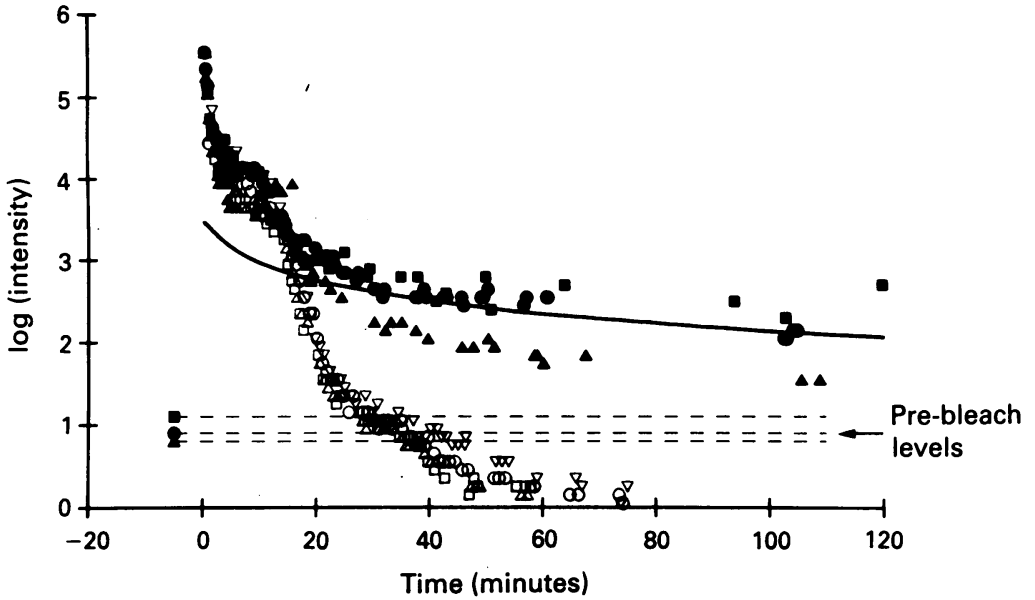

Figure 5 Dark adaptation curves measured under similar conditions to Figures 2 and 3 showing the results from three patients (subjects $1,4,8$ ) compared with normal controls (open symbols). These patients are illustrated since dark adaptation was recorded for more than 100 minutes. The pre-bleach thresholds are indicated by the horizontal lines. The solid curve represents the results of the calculation of the effect on threshold of outer segment renewal (see text). normal time course of the early phase of recovery of rod sensitivity is more readily explained by the second; if shedding were not complete and in situ regeneration of rhodopsin occurred normally in the small residual outer segment, initial rod dark adaptation would be normal as seen in our patients. The similarity between the recovery of sensitivity predicted by the model and that seen in our patients suggests that outer segment renewal contributes to recovery after light adaptation in some patients. To date this mechanism of recovery from strong light adaptation has received little attention, and is worthy of further study.

The model requires that the outer segments are short as a results of RP and that a major portion of the outer segment is shed following strong light adaptation. The mechanism by which alteration of the amino acid sequence of the rod opsin molecule may influence outer segment structure or stability remains to be elucidated. The phenomenon occurs with different mutations in the rod opsin molecule, although all mutations associated with this pattern of disease recorded to date are on the first exon, and it is quite possible that similar functional defects may be found with defects on other genes.

We are grateful to Professor Barrie Jay and Dr Marcelle Jay for helpful discussion during the preparation of this paper. Thanks

also to Brenda Lauffart for expert technical assistance.
This work was supported by the National Pigmentosa Foundation Fighting Blindness USA, British Retinitis Pigmentosa Society, Medical Research Council (UK). The University and the Special trustees of the Royal Victoria Infirmary, Newcastle upon Tyne. rod sensitivity would depend largely or formation of new outer segment discs with their normal concentration of rhodopsin. In favour of the latter is the suggestion that night blindness in some forms of RP may be caused by progressive shortening of the rod outer segment due to an imbalance between disc shedding and renewal, ${ }^{35}$ and the identification of shortened rod outer segments in autosomal dominant RP in a histological study..$^{36}$ Using data from primate studies of rod outer segment length and disc turnover, ${ }^{37}$ the recovery of rod sensitivity due entirely to regrowth of photoreceptor discs can be calculated. It is possible then to model the effect of different rod outer segment lengths and different rates of renewal on recovery of rod sensitivity. Here we have considered a simple model of an outer segment length of $0.01 \mu \mathrm{m}$ following intense light adaptation and assumed normal outer segment renewal of $3 \mu \mathrm{m}$ per day. The predicted recovery of rod sensitivity with formation of new outer segment discs can be calculated using the quantum catch relationship ${ }^{4}$ (Fig 5). Using this simple model there is a good fit between the predicted recovery of rod sensitivity and that actually measured in our subjects during the entire abnormal late phase of rod adaptation.

Thus, the very slowed late phase of rod dark adaptation seen in our subjects, may be explained by the regrowth of rod outer segments with their normal concentration of rhodopsin. The data do not distinguish between the two possible mechanisms, namely failure to regenerate rhodopsin on existing outer segment disc membranes and light induced shedding restricting available membrane. However the
1 Massof RW, Finkelstein D. Two forms of autosomal dominant retinitis pigmentosa. Doc Ophthalmol 1981; 51: 289-346.

2 Lyness L, Ernst W, Quinlan MP, Clover GM, Arden GB, Carter R, et al. A clinical, psychophysical, and electroretinographic survey of patients with autosomal dominant retinitis pigmentosa. Brf Ophthalmol 1985; 69: 326-39.

3 Jacobson SG, Voigt WJ, Parel JM, Apathy PP, Ngheim-Phu L, Myers SW, et al. Automated light and dark-adapted perimetry for evaluating retinitis pigmentosa. Ophthalmology 1986; 93: 1604-11.

4 Kemp CM, Faulkner DJ, Jacobson SG. Rhodopsin levels in autosomal dominant retinitis pigmentosa. Invest Ophthalmol Vis Sci 1988; 29: 1235-41.

5 Berson EL, Howard J. Temporal aspects of the electroretinogram in sector retinitis pigmentosa. Arch Ophthalmol 1971; 48: 653-65.

6 Massoff RW, Finkelstein D. Vision threshold profiles in sector retinitis pigmentosa Arch Ophthalmol 1979; 97: 1899-904.

7 Fulton $A B$, Hansen RM. The relationship of rhodopsin and scotopic retinal sensitivity in sector retinitis pigmentosa. $\mathrm{Am}$ f Ophthalmol 1988; 105: 132-40.

8 Lester DH, Inglehern CF, Bashir R, Ackford H, Esakowitz L, Jay M, et al. Linkage to D3S47 (C17) in one large dominant retinitis family and exclusion in another: confirmation of genetic heterogeneity. Am f Hum Genet 1990; 47: 536-41.

9 Dryja TP, McGee TL, Reichel E, Hahn IB, Cowley GS, Yandel DW, et al. A point mutation of the rhodopsin gene in one form of retinitis pigmentosa. Nature 1990; 343: 364-6.

10 Inglehearn CF, Jay M, Lester DH, Bashir R, Jay B, Bird AC, et al. No evidence for linkage between late onset autosomal dominant retinis dominant retinitis pigmentosa and chromosome 3 locus D3S47 (C17): evidence for genetic heterogeneity. Genomics $\mathrm{CT}$, McKneown CME, et al. Close genetic linkage between $\mathrm{X}$-linked retinitis pigmentosa and a restriction fragment
length polymorphism identified by recominant DNA probe L1.28. Nature 1984; 309: 253-5.

12 Ott J, Bhattacharya S, Chen JD, Denton MJ, Donald J, Dubay C, et al. Localizing multiple X chromosome-linked retinitis pigmentosa loci using multilocus homogeneity tests. Proc Natl Acad Sci USA 1990; 87: 701-4.

13 Dryja TP, McGee TL, Hahn LB, Cowley CG, Olsson JE, patients with autosomal dominant retinitis pigmentosa. $N$ Engl F Med 1990; 323: 1302-7. Jacobson SG, Heckenlively JR, et al. Rhodopsin mutations in autosomal dominant retinitis pigmentosa. Proc Natl Acad Sci 1991; 88: 6481-5.
11 Bhattacharya SS, Wright AF, Clayton JF, Price WH, Phillips Reichel E, et al. Mutations within the rhodopsin gene in

14 Sung CH, Davenport CM, Hennessey JC, Maumenee $\mathbf{1 H}$, 
15 Heckenlively JR, Rodrigues JA, Daiger SP. Autosomal dominant sectoral retinitis pigmentosa, two families with transversion mutation in codon 23 of rhodopsin. Arch Ophthalmol 1991; 109: 84-91.

16 Berson EL, Rosner B, Sandberg MA, Dryja TP. Ocular findings in patients with autosomal dominant retinitis pigmentosa and a rhodopsin gene defect. Arch Ophthalmol pigmentosa and a

17 Weleber RG, Murphey WH, Rodrigues JA, Lovrien EW, Lit M, Daiger SP. Phenotypic expression of the Pro23His mutation of rhodopsin in a large family with autosoma dominant retinitis pigmentosa. Invest Ophthalmol Vis $\mathrm{Sc}$ 1991; 32 (Suppl): 913

18 Fishman GA, Stone EM, Gilbert LD, Kenna P, Sheffield VC. Ocular findings associated with a rhodopsin gene transversion mutation in autosomal dominant retinitis pigmentosa. Arch Ophthalmol 1991; 109: 1387-93.

19 Jacobson SG, Kemp CM, Sung CH, Nathans J. Retinal function and rhodopsin levels in autosomal dominant retinitis pigmentosa with rhodopsin mutations. Am $\mathcal{f}$ Ophthalmol pigmentosa with

20 Kemp CM, Jacobson SG, Roman AJ, Sung CH, Nathans J. Abnormal rod adaptation in autosomal dominant retinitis pigmentosa with Pro-23-His rhodopsin mutation. Am Ophthalmol 1992; 113: 165-74.

21 Farrar GJ, Jordan SA, Kenna P, et al. Autosomal dominan retinitis pigmentosa; localization of a disease gene (RP6) to the short arm of chromosome 6. Genomics 1991; 11: 870-4.

22 Blanton SH, Heckenlively JR, Cottingham AW, et al. Linkage mapping of autosomal dominant retinitis pigmentosa (RPI) to the pericentric region of human chromosome 8 . Genomics 1991; 11: 857-69.

23 Farrar GJ, Kenna P, Jordan SA, Kumar-singh R, Humphries MM, Sharp EM, et al. A three-basis-pair deletion in the peripherin-RDS gene in one form of retinitis pigmentosa. peripherin-RDS gene in one

24 Kajiwara K, Hahn LB, Mukai S, Travis GH, Berson EL Dryja TP. Mutations in the human retinal degeneration slow gene in autosomal dominant retinitis pigmentosa. Nature 1991 ; 354: 480-3.

25 Arden GB, Carter RM, Hogg CR, Powell DJ, Ernst W, Clover
GM, et.al. A modified ERG technique and results obtained in X-Linked retinitis pigmentosa. Brf Ophthalmol 1983; 67: 419-30.

26 Ernst W, Faulkner DJ, Hogg CR, Powell DJ, Arden GB Vaegan. An automated static perimeter/adaptometer using light

27 Keen TJ, Lester DH, Inglehearn CF, Curtis A, Bhattacharya SS. Rapid detection of single base mismatches as heteroduplexes on hydrolink gels. Trends Genet 1991; 7: 5 .

28 Keen TJ, Inglehearn CF, Lester DH, Bashir R, Jay M, Bird $\mathrm{AC}$, et al. Autosomal dominant retinitis pigmentosa: four mutations in rhodopsin, one of them at the retinal attachment site. Genomics 1991; 11: 199-205.

29 Zeavin BH, Wald G. Rod and cone vision in retinitis pigmentosa. Am 7 Ophthalmol 1956; 42: 253-69.

30 Goodman G, Gunkel RD. Familial electroretinographic and adaptometric studies in retinitis pigmentosa. Am $\mathcal{F} O$ phthal mol 1958; 46: 142-72.

31 Alexander KR, Fishman GA. Prolonged rod adaptation in retinitis pigmentosa. Br 7 Ophthalmol 1984; 68:561-9.

32 Ernst $W$, Moore AT. Heterogeneity. and incomplete penetrance in autosomal dominant retinitis pigmentosa. In: Zrenner E, Krastel $\mathrm{H}$, Goebel H-H, eds. Research in retinitis pigmentosa. Oxford: Pergamon, 1988 115-20.

33 Ripps H. Night blindness revisited: from man to molecules. Invest Ophthalmol Vis Sci 1982; 23: 588-609.

34 Sharp D, Arden GB, Kemp CM, Hogg CR, Bird AC. Mechanisms and sites of loss of scotopic sensitivity: a clinical analysis of 1990; 5: 217-30.

35 Ripps H, Brin KP, Weale RA. Rhodopsin and visual threshold in retinitis pigmentosa. Invest Ophthalmol Vis Sci 1978; 17: in retin -45 .

36 Flannery JG, Farber DB, Bird AC, Bok D. Degenerative changes in a retina affected with autosomal dominan retinitis pigmentosa. Invest Ophthalmol Vis Sci 1989; 30: 191-211.

37 Young RW. The renewal of rod and cone outer segments in the rhesus monkey. 7 Cell Biol 1971; 49: 303-8. 